Session 2238

\title{
Defining Expertise in the Use of Constraint-based CAD Tools by Examining Practicing Professionals
}

\author{
Nathan W. Hartman \\ Purdue University
}

\begin{abstract}
Academic engineering graphics curricula are facing a rapidly changing knowledge base and current teaching and assessment methods are struggling to keep pace. Engineering graphics curricula within an academic setting should examine industry-based techniques in an effort to improve classroom instruction. This paper is the second in a two-part series which examines practicing engineering graphics professionals to discover their experiences in developing expertise in the use of constraint-based CAD tools. Based on a study conducted in the fall of 2002, it presents the results of a knowledge-mapping task and think-aloud modeling task used with each participant to examine their modeling strategies used in creating a 3D model and their organization of the concepts surrounding this knowledge domain of constraint-based CAD tools. The results of the think-aloud modeling task yielded five specific modeling procedures which were distilled into one common modeling procedure for the given object. In addition, the results of the knowledge mapping task revealed five separate knowledge maps, and the common elements from each one were combined to form a generic knowledge map related to the use of constraint-based CAD tools. These two sets of results comprised the initial elements used to define expertise in the use of constraint-based CAD tools based on these five participants. The discussion presented in this article provides an initial look at an approach to creating geometry with constraint-based CAD tools, as well as specific topics to be included in a curriculum that includes constraint-based CAD tools. These conclusions also suggest specific potential teaching and assessment methodologies.

Introduction

The engineering design graphics curriculum is at a crossroads. Computer technology is enabling engineers and technicians to design and manufacture parts without relying on two-dimensional drawings. However, the curricula at many universities and community colleges still dedicate a great deal of time focusing on 2D documentation drawings, and this is even more evident at the high school level. There are several possible reasons why some programs have not changed to a curriculum that focuses on constraint-based, three-dimensional solids modeling, including $\operatorname{cost}^{1}$, pedagogical issues ${ }^{2}$, and traditional dogma ${ }^{3}$. Where in the past drawings were critical components of the design process, today they tend to be ancillary documents. The
\end{abstract}

Proceedings of the 2004 American Society for Engineering Education Annual Conference \& Exposition Copyright (C) 2004, American Society for Engineering Education 
Session 2238

aforementioned reasons for not revising the engineering graphics curricula that are taught within the university environment has left the profession in a position where it is at risk of being surpassed by the rate of technological change. Only recently has the profession developed a mindset of reform. However, the focus of CAD technology is changing; CAD technology is now being used to capture and store information that is critical to the definition of the product ${ }^{4,5}$. No longer are Boolean-based primitive CAD systems prevalent in the engineering design process ${ }^{6}$.

At the national level, several formal and informal curriculum revision activities are taking place to address the need for integration of constraint-based CAD into the curriculum ${ }^{7,1,8,9}$. Along with traditional topics, such as visualization skills and standards, 3D constraint-based solid modeling is being considered an important topic. In addition, applied and theoretical knowledge of engineering graphics are also being emphasized. Even with the onset of these new developments in curriculum integration, how are these tools being used? Is there an emphasis on menu selections or comprehensive strategies? Duff ${ }^{10}$ suggested that engineering graphics could be taught as a body of knowledge independent of specific tools. The tools that existed within the traditional engineering graphics discipline have changed, and just as there were strategies suggested for the use of drafting equipment in most major engineering graphics textbooks, there needs to be effective strategies developed for the use of constraint-based CAD tools.

The reason that most companies have adopted 3D CAD is its overwhelming advantages over 2D drafting: mass properties, visualization, accuracy, etc. ${ }^{6}$. But at the beginning of the transition phase to 3D CAD, many CAD users still carry the mindset of using drawings as the basis of their work. They still used slide rules, calculators, and handbooks to find and process much of their needed information ${ }^{4}$. Because of the lack of effective education and training in both the academic and professional settings, many constraint-based CAD tool users have not developed effective strategies for utilizing the software. In addition, many third-party training seminars or university engineering graphics courses are not espousing best practices either ${ }^{1}$. They are strictly concerned with users developing proficiency with selection of menu picks and software commands. While some users have become experts at using this type of software and approach, the vast majority of them have not. Some of them do not need to be experts, but most of them should be more proficient ${ }^{11}$. So it is imperative that the CAD user develop effective problemsolving strategies to accommodate the fluctuation in design variables which typically affect their design environment.

Given that engineering and technology students will likely be employed in a commercial engineering or design environment, effective use of these tools needs to be promoted. In order to uncover the inherent knowledge base behind the use of these tools and the techniques and strategies associated with using them, an examination of professional expert usage was conducted. The purpose of this exploratory research study was to explore the definition and development of expertise in the use of constraint-based CAD tools by examining practicing

Proceedings of the 2004 American Society for Engineering Education Annual Conference \& Exposition Copyright C 2004, American Society for Engineering Education 
Session 2238

professionals. In addition, what are the critical concepts that comprise the mental model and the software techniques of expert, constraint-based CAD users?

\section{Relevant Literature}

To address the questions regarding the definition of expertise in the use of constraint-based CAD tools, a literature review was undertaken to examine the many facets of expertise, including perspectives from cognitive psychology, sociology, and technology. The cognitive examination of expertise focused mainly on information processing theory, which examines the means by which humans process sensory information and encode it for storage into long-term memory ${ }^{12}$. This affects problem solving strategies, as well as mental models of how a knowledge base is defined and implemented ${ }^{13}$. This assimilation of past knowledge and present information and relevant factors forms the basis of mental model development. From these mental models and their inherent structures, experts are able to solve problems. Developing expertise is an ongoing process of the acquisition and refinement of skills and knowledge that are needed within a particular domain of life ${ }^{14}$.

Much research has been done in the way of analyzing expertise and its various properties ${ }^{15,16,17}$. Experts tend to excel within particular knowledge areas, and they perceive large and meaningful patterns to their domain knowledge. Experts also tend to solve problems quickly with fewer errors, and they have superior long- and short-term memory skills. Development of an extensive problem scope, the ability to see that problem at a deeper level, and the ability to monitor their path towards a solution are also characteristics of experts within a given field ${ }^{18}$. Expertise is also viewed not just as an attribute of a particular person, but also by the way a person is perceived by other people within their professional setting ${ }^{19}$. In this case, expertise is a labeling function applied to a person or group by another person or group.

All of the perspectives from which expertise was examined address the notion of practical intelligence and the fact that, in most cases, expertise is gauged within the specific context of a particular domain. This domain is what gives the individual the framework by which to assimilate new information to existing knowledge. Practical intelligence is also linked to the strategic use of tools, and constraint-based CAD is no exception. Several studies have examined the use of CAD from a two-dimensional, architectural point of view, but the study of constraintbased CAD is lacking in this area ${ }^{20,21,22,23}$. Thus, this study was an initial attempt at addressing some of these issues.

\section{Procedures}

To address the development of expertise in the use of constraint-based CAD, this study used two methods of data collection with each participant: a think-aloud modeling task and a knowledgemapping task. The think-aloud protocol was used as a means to examine the problem-solving process employed by the participants in the creation of constraint-based CAD models. In doing 
Session 2238

so, the researcher attempted to uncover the relationship between the expert's mental model and the actions they actually performed when modeling an object. A form of protocol analysis ${ }^{24}$ called a think-aloud protocol was used to analyze the transcripts for each problem solving session to determine common language and methods used in the process. Each participant was given the same written modeling scenario with an accompanying figure, and they were asked to create a 3D solid model of the STOCK SUPPORT BASE shown in the assembly in Figure 1. They were to use the additional given parts and the problem scenario for reference as necessary. The transcripts of these sessions were then analyzed for the common steps used to make the model and the order in which they were performed. The goal of this analysis was to examine the modeling procedures used by the expert participants to create geometry within the CAD tool and to determine a common modeling procedure if possible.
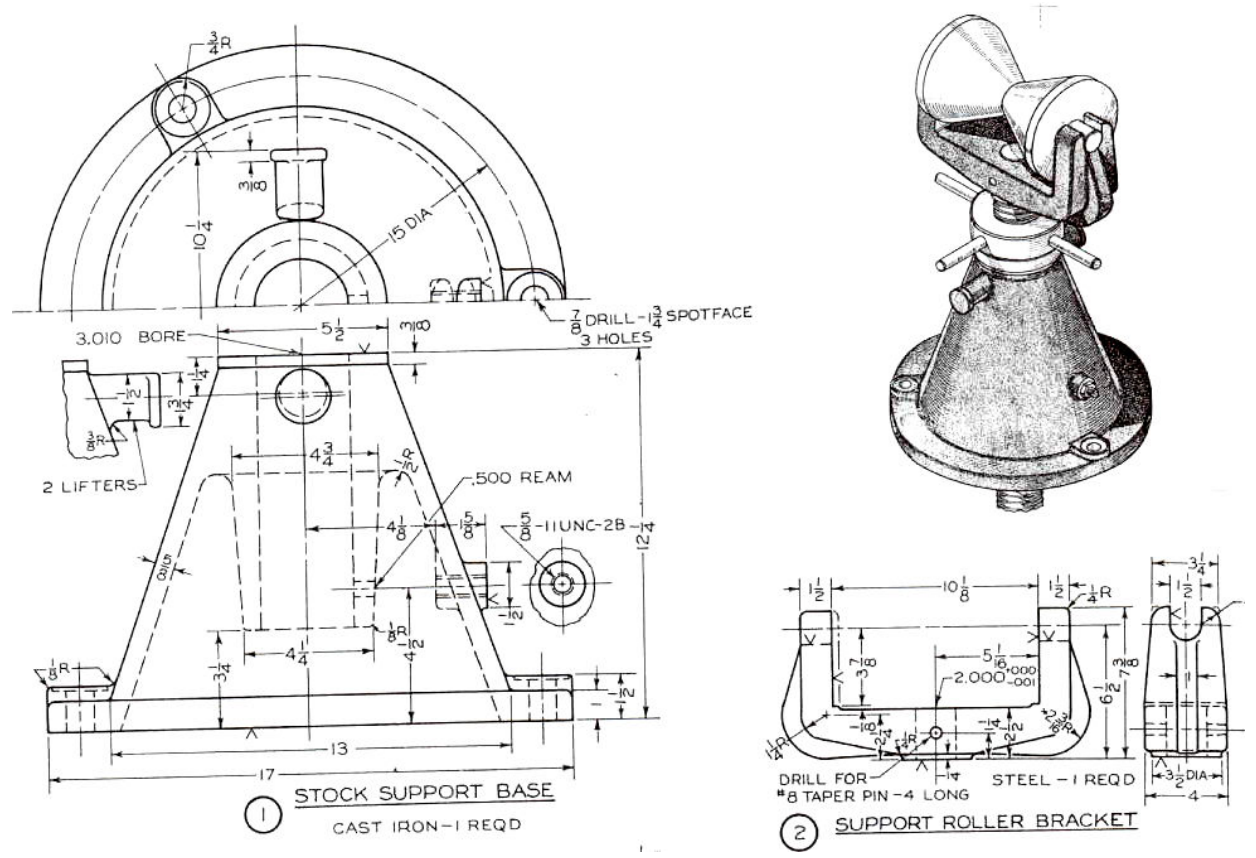

Figure 1: Think Aloud Modeling Task Figure - STOCK SUPPORT BASE ${ }^{25}$

The knowledge mapping tasks were conducted with each participant in an effort to create a view of their mental model with respect to the domain of constraint-based CAD. This was accomplished by labeling a series of cards with common terms and phrases, taken from constraint-based CAD literature, the experience of the researcher, and the observations of each participant, and asking each participant to arrange them based on their conceptions and perceptions of the importance of and relationships between the concepts. Participants were

Proceedings of the 2004 American Society for Engineering Education Annual Conference \& Exposition Copyright (C) 2004, American Society for Engineering Education 
Session 2238

allowed to add or remove items form this list as necessary. The goal of this analysis was to determine the relationships and structure of the critical concepts within the higher-level knowledge domain surrounding constraint-based CAD tools ${ }^{24,26}$. A graphical representation of each participant's arrangement was created to form a knowledge map, which was then compared and combined with those from the other participants to attempt to create a common mental model of constraint-based CAD. Table 1 includes a list of the terms that were used.

Table 1

List of Terms for Knowledge Mapping Task

\begin{tabular}{|c|c|c|c|}
\hline 1. Feature & 25. Blend (Loft) & 49. Boolean & 73. Mass Properties \\
\hline 2. Part & 26. Model Interrogation & $\begin{array}{l}\text { 50. Downstream Use } \\
\text { Model }\end{array}$ & 74. Measure (Command) \\
\hline 3. Assembly & 27. Regen Info (Roll Back & 51. Relations (Equations) & 75. Spatial Envelope \\
\hline 4. Drawing & 28. Model Tree (Feature Tree) & 52. Sketch (Profile) & 76. Interaction $\mathrm{b} / \mathrm{w}$ Parts \\
\hline 5. Protrusion (Boss/Base) & 29. Parent/Child Ref. Info & 53. Sketching Plane & 77. Dimensioning \\
\hline 6. Cut & 30. Surface Geometry & 54. Origin & 78. Parametric \\
\hline 7. Round (Fillet) & 31. Skeleton & 55. Pattern(s) & 79. Constraint-based \\
\hline 8. Draft & 32. Modeling Standards & 56. Associativity & 80. Feature-based \\
\hline 9. Shell & 33. Manufacturing Proc. & 57. Component & 81. Threads (Cosmetic) \\
\hline 10. Datum Plane & 34. IGES & 58. PDM & 82. Parameter \\
\hline 11. Datum Axis & 35. Simplified Rep & 59. Base Feature & 83. Dimension-driven \\
\hline 12. Parent/Child Reference & 36. Customer Requirements & 60. Family Table & 84. Feature Order \\
\hline 13. Design Intent & 37. Assembly References & 61. Instance(s) & 85. Modeling Procedure \\
\hline 14. Modify & 38. Datum Curves & 62. Moldflow Analysis & 86. Centerline \\
\hline 15. Redefine (Edit Sketch) & 39. Past Experiences & 63.FEA & 87. Regenerate (Rebuild) \\
\hline 16. Reorder & 40. Geometric Construction & 64. CFD & 88. Delete \\
\hline 17. Failure Mode/Error & 41. Drafting & 65. Sheetmetal & 89. Visualization \\
\hline 18. Inset Mode & 42. Constraints (Relations) & 66. Over-constrained & 90. Default Datum Pln.* \\
\hline 19. Roll Back Model & 43. Sketching References & 67. Under-constrained & 91. Geometry Creation* \\
\hline 20. Use Edge (Convert Entities) & 44. Sketching Orientation & 68. Coordinate System & 92. Geometry Editing* \\
\hline 21. Offset Edge & 45. Blind & 69. Group & 93. Suppliers* \\
\hline 22. Extrude & 46. Through All & 70. Copy & 94. Application of Part* \\
\hline 23. Revolve & 47. Up to Surface & 71. Mirror & 95. Material Selection* \\
\hline 24. Sweep & 48. Primitive Geometry & 72. Suppress & 96. Chamfer** \\
\hline
\end{tabular}

* Added by Participant 1

** Added by Participant 4

Due to the fact that a localized concentration of experts within a domain is rarely if ever found, this research study used a smaller sample size than those used in experimental research designs. Experts were selected using a variety of criteria including their time in a particular job and their status as a practicing professional ${ }^{27}$. In fact, Polkinghorne ${ }^{28}$ and Meyer and Booker ${ }^{29}$ recommended the analysis of between five and twenty participants for an exploratory phenomenological study. Potential companies to draw participants from were identified by the

Proceedings of the 2004 American Society for Engineering Education Annual Conference \& Exposition Copyright (C) 2004, American Society for Engineering Education 
Session 2238

researcher based on suggestions made by the Engineering Design Graphics Division of the American Society for Engineering Education and by RAND Worldwide, a leading engineering consulting company. Contact was made with human resources and engineering management personal in order to have them nominates people within their respective companies as potential participants for the study. As a result, five experts were selected based on their experiences and their status as practicing professionals, years of experience in the engineering design field, years of experience using the $\mathrm{CAD}$ tool, and educational background. Following is a brief description of each of the five participants:

- Participant 1 was a thirty-one year old design engineer for a company that designs and manufactures pumping products for the commercial water filtration and swimming pool markets. He holds a bachelor's degree and a master's degree from a foreign institute of technology, both of which are in mechanical engineering, and he is considered the resident constraint-based CAD expert in his group. Pro/ENGINEER was used at this company.

- Participant 2 was a twenty-four year old design engineer with a bachelor's degree in mechanical engineering, and he works for a multi-national corporation that designs and manufactures heavy equipment for the construction and transportation industries. He works in a large group with several other resident experts. Pro/ENGINEER was used at this company.

- Participant 3 was a fifty year old design engineer for a company that designs and manufactures custom packaging and cases for consumer products. He holds a bachelor's degree and a master's degree, both of which are in technology, and he works in a group with two other people - his boss and one coworker. Pro/ENGINEER was used at this company.

- Participant 4 was a fifty year old senior designer with an associate's degree in drafting and design. He works in a large design group with several other people who have access to constraint-based CAD tools and uses it on a daily basis. It is a multi-national corporation that designs and manufactures electrical components for residential and commercial applications. Pro/ENGINEER was used at this company.

- Participant 5 was a twenty-eight year old designer for a company that designs and manufactures inoculation equipment for the poultry industry. He works in a group that consists of himself, his boss, and four other designers; however they do interface on a regular basis with the vendors that fabricate their parts. Participant 5 has a bachelor's degree in industrial technology and mechanical drafting and design. SolidWorks was used at this company.

Findings

The findings presented in this paper are based on the data collected from five participants employed as practicing professionals in the engineering design domain. It was assumed that each of them had the following requisite expert characteristics to provide meaningful data for this study:

- Each participant had some form of technical training past the high school level.

Proceedings of the 2004 American Society for Engineering Education Annual Conference \& Exposition Copyright (C) 2004, American Society for Engineering Education 
Session 2238

- Each participant had at least three (3) years of experience in the use of constraint-based CAD tools as a practicing professional.

- Each participant used the constraint-based CAD tools for an average of fifteen (15) hours per week.

- Each participant worked in a product design environment with selection preference given to those individuals designing cast, forged, machined, or plastic parts.

- Each participant typically worked with assembly models containing more than ten (10) components.

Think Aloud Modeling Task - Examination of the usage of the software tool and its inherent processes was done through the use of the think-aloud modeling task to gain a level of insight into the modeling procedures used by these five participants. In examining the procedures used by each participant, it appears that the choices they made with regard to creating and editing geometry were a result of several factors. Each participant had a choice when creating the individual features in their model, which was based on the attributes, aspects and attractiveness of the contributing factors, such as function of the part and the inherent geometric forms contained within it. It appears that each one of them gave consideration to the inherent geometry of the part, as well as the function of the model. Each participant examined the accompanying parts in the assembly in addition to the one they were asked to model.

According to the participants' modeling procedures, feature order impacted the appearance of the finished geometry, as well as the ability to modify existing features. Some participants decided to create as much geometry as possible within that first feature operation, while others decided to create separate features. The references used for the creation of each feature impacted the ability to later modify and edit the geometry, as well as the ability to capture design intent during creation. While some participants were adamant about selecting default datum planes to serve as sketching planes for the features they created, others decided to select existing part surfaces to establish the position and orientation of their features. In doing so, each participant had to consider the aspects of selecting a particular sketching plane and the effects that would have on their model later.

Each feature contained attributes including aspects of sketching plane orientation, feature type, feature order, and sketched geometry. Each person selected one of the default vertical datum planes on which to sketch the first revolved profile due to the default vertical orientation of the part. The selections for sketching planes for subsequent features were based not only on the desired future orientation of that feature, but also on the references to other features as mentioned previously. By being able to recognize inherent geometry within the model, each participant was able to effectively choose a feature type for each of the features in their model. While this was relatively simple for them, their methods for creating certain features varied. Some participants decided to create various features on the model separately and copy them,

Proceedings of the 2004 American Society for Engineering Education Annual Conference \& Exposition Copyright (C) 2004, American Society for Engineering Education 
Session 2238

while other decided to create the duplicate geometry as part of one complex feature. Feature order also played a role in the participants' choices for creating and duplicating geometry. Noticeable differences were seen here in terms of strategy for feature duplication regarding those participants who used Pro/ENGINEER and the participant who used SolidWorks. Each of the participants made some type of decision regarding their use of specific commands that would allow them to work at a particular speed, particularly in the areas of the model that afforded them the opportunity to use feature duplication techniques within the software. Given the procedural and relational nature of these software tools, each participant adopted a strategy for modeling the STOCK SUPPORT BASE shown in Figure 1 that enabled them to maximize the attractiveness of certain choices the software and the modeling scenario presented to them. They considered the inherent geometry and default orientation of the part in deciding how to make the first feature. Once they decided on the revolved solid feature, they selected an appropriate sketching plane upon which to sketch a profile.

It appeared that the modeling techniques employed by these five participants were similar in the creation of the given object. Each of them considered past experience with a particular command and how that impacted their ability to create geometry easily and accurately. The participants also considered potential changes to the model and how these could be accommodated given the functionality of the software. Feature order, parent/child references, and sketched geometry were all considerations at this point. They coupled this knowledge with the information presented in the given situation to develop a strategy for creating the STOCK SUPPORT BASE, which would capture the design intent of the model and the inherent characteristics of the geometry. Their resulting modeling procedures focused on the capture of critical dimensions included in the overall nature of the part geometry, and the embedded relationships of the subsequent features used to finish the full description of the part geometry. The part modeling strategy of each participant generally focused on the creation of features which added material to the model first. Those features which removed material from the model tended to be created in a "secondary" fashion after much of the aforementioned geometry was in place.

Selection of the base feature was critical to the modeling process of each participant. It influenced the parent/child references established within the model as well as the orientation adopted by the finished model. This was the geometry from which all of the other features in the model were referenced. Once the decision had been made regarding what would become the first feature, subsequent features were created that either added or removed material from the model. Each sketched feature in the model was created using a similar procedure. The following modeling procedure emerged from the analysis of the data provided by these five participants:

1. Determine sketching plane

2. Sketch profile

3. Add constraints/relations

Proceedings of the 2004 American Society for Engineering Education Annual Conference \& Exposition Copyright (C) 2004, American Society for Engineering Education 
Session 2238

4. Add dimensions

5. Apply feature form

Knowledge Mapping Tasks - While the knowledge-mapping task produced its own discrete data to be analyzed and its own set of findings related to the structure of the five participants' knowledge of constraint-based CAD tools, it also provided a useful summation to the examination of this phenomenon. While analyzing the knowledge maps for each participant, it became apparent that their knowledge of their respective constraint-based CAD tools was both procedural and declarative, which closely follows the characteristics suggested by Bhavnani ${ }^{22,23}$ in his examination of the use of 2D CAD tools. While the functionality of the tools has certainly grown more complex, the basic use of the tool has not: geometry creation. While the nature of the use of the CAD tools has changed over time, the reasons for their use have not: speed, accuracy, and capture of design information.

The participants tended to classify items into groups that represented factual items or concrete elements of the geometry, such as Cut, Boss, or Round, and also the procedural nature of the software, such as Extrude, Revolve, and Pattern. As they sometimes struggled to place certain concepts within the map that they had developed, they could never break the bond between the procedural nature of the commands and the declarative result they would obtain. Even software operations that exhibited the use of strategy on the part of the participant were always described in terms of what was required from a procedural or declarative standpoint to make it function properly.

Heavily influencing the decision to place a concept in a particular group, especially related to geometry creation, was past experience and fundamental understanding of the core characteristics of the software itself. While each participant had his own manner in which he characterized his model, the beginning of that description typically started with a discussion of the broad explanation of these tools. The impact that associativity, constraint-based geometry, dimension-driven geometry, and parametric geometry had on the majority of their decisions in terms of how to capture design intent with the model typically pervaded any discussion of feature creation, duplication, and modification.

In examining the knowledge maps of these five participants related to the use of constraint-based CAD tools it appears that they have several common characteristics. Each of the participants accounted for concepts related to the direct usage of the CAD tool as well as the background or general information. While each participant accounted for the specific conceptual elements in these large categories in slightly different ways, it was apparent that many of the concepts were interrelated on a variety of levels. For example, the concepts of past experience, design intent, customer requirements combined with knowledge of the fundamental processes of the software to dictate the choices for geometry creation.

Proceedings of the 2004 American Society for Engineering Education Annual Conference \& Exposition Copyright (C) 2004, American Society for Engineering Education 
The notions of dimension-driven, parametric, associativity, and constraint-based directed the selection and creation of specific feature types, feature forms, and depth options. Knowledge of parent/child references and geometric constraints also influenced the manner in which geometry was edited and duplicated. In order to investigate the ramifications of certain geometry creation and editing strategies, each participant appeared to use some form of geometry interrogation tool to gather information within the CAD tool. Each of the participants expressed their view of the use of the CAD tool as being goal oriented, to produce a model that could be used throughout the design process. Communications with team members, suppliers, and vendors through the use of drawings derived from the CAD model or by simply sharing CAD data back and forth were mentioned several times as downstream uses for the model. Several participants also mentioned using the CAD tool as the input for analysis of the design, as well as archiving the model for maintenance of the design database. Figure 2 represents a common knowledge map based on the major categories from the five participants in this study, which closely parallel the conception of engineering and design knowledge suggested by Vincenti ${ }^{30}$.

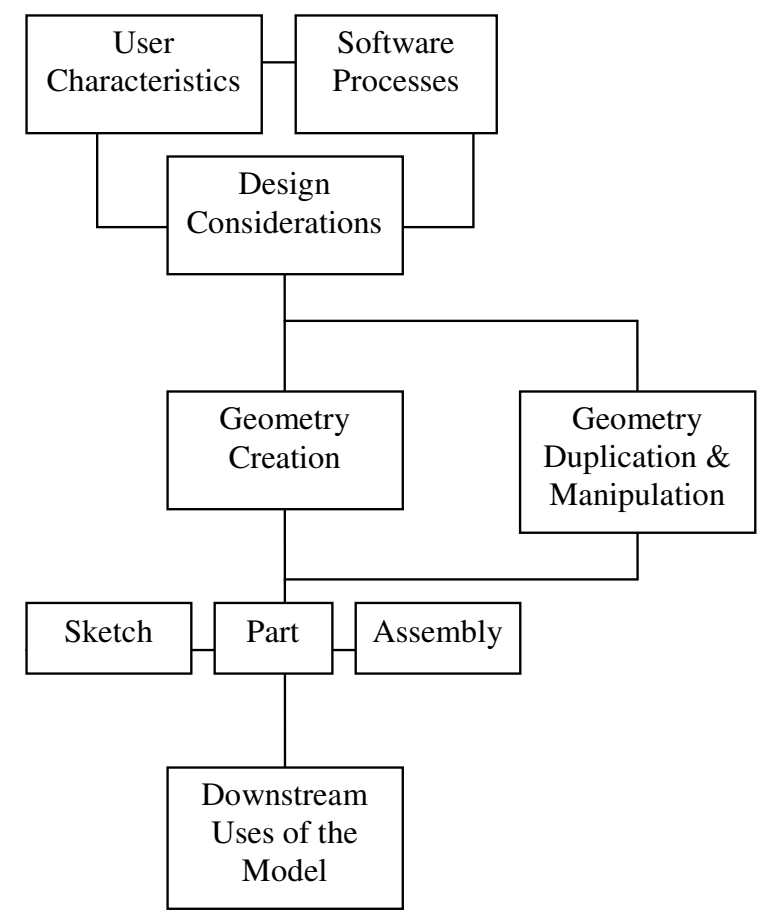

Figure 2: Common Knowledge Map for Participants

Implications for Engineering Graphics Education

Upon examination of past experiences related to these five participants, it appears that expertise is developed by authentic activities within the context of the engineering environment, as well as 
Session 2238

the opportunity to be immersed in the used of constraint-based CAD tools during their educational process. The characteristics possessed by these five participants appear to be similar to those of experts in other disciplines, particularly with respect to problem scope and definition, the ability to gather information to develop a problem-solving strategy, and the ability to recognize the boundaries of one's own knowledge base.

This study provides a glimpse of the basic modeling procedures for creating geometry within the CAD tool based on the inherent characteristics of the geometry of the product to be designed and the strategy developed by the user to create such geometry. Finally, this study provides a very general, highly conceptual view of the knowledge base that underlies these tools. Its emphasis is on the fact that using these CAD tools combines knowledge about the CAD tool, as well as engineering knowledge, to develop a means to address geometry creation and manipulation in the course of creating a model to be used throughout the engineering design process.

In addressing the issues of tool usage and strategy, the definition of expertise in the use of constraint-based CAD tools as evidenced by the modeling procedures of these five participants appears to be composed of "knowing how" and "knowing what." This includes knowledge of geometry creation, manipulation, and editing techniques coupled with information about the design considerations that surround the model creation. Not only did the participants exhibit knowledge of the engineering domain, but also fundamental knowledge of the software, which in most cases was impacted by past experiences and their own individual characteristics. This becomes apparent when examining Figure 2. The combination of tacit engineering knowledge with declarative and procedural software knowledge leads to a strategic use of the tool to complete a goal-oriented design process. Educational activities that involve the creation of CAD models to fulfill a specific purpose, as well as the modification of those models according to specified criteria, would coincide with these specific findings. Assessing the model according to its desired behavior and the relationships between its inherent features would be critical. Educational activities might include asking students to sketch (paper-and-pencil based) a modeling procedure for a given object based on geometric primitives or feature profiles, to create a model that must later be modified, without feature failure, in order to accommodate variations in the geometry and requisite behavior of the model, or to ask student to make changes to each other's models thereby making critical the use of geometry interrogation functions within the CAD tool. While these examples are but a few of the many options for educators, a primary focus any modeling assignment should be the complete geometric and dimensional constraint of the features in a model.

New users of a particular software package should focus on establishing a problem context and definition that encompasses the factors surrounding the design. Situations that include geometry creation and redefinition, as well as geometry modification and manipulation, should be provided to prepare new users for the complexity of the design situation. As educators, we 
Session 2238

should provide our students with a written problem scenario which describes the basic "ground rules" for the assignment, but leaves open other variables that would force students to contemplate the development of a modeling strategy based on the desired behavior of the model. Establishing common modeling procedures for creating similar types of geometry would also be beneficial. The participants in this study made no secret that creating the model was just one part of the design process, even though it bears a great deal of significance. Student activities should center on context-specific activities that force them to use their models for something other than display purposes. Moving CAD data between software packages, using models to create prototypes and drawings, and generating machine tool code from the surface data in the model would all be legitimate examples of authentic design activities. While it will take extra effort on the part of the instructor, educational activities should be developed that place the student into a context in which the model exists and that defines the model's acceptability and level of "correctness" based on its response to anticipated and unforeseen design changes.

Bibliography

1. Miller, C. L. (1999). New technologies for engineering graphics. Proceedings of the 53 ${ }^{\text {rd }}$ Midyear Conference of the Engineering Design Graphics Division of the American Society for Engineering Education, Columbus, Ohio, January 15-17, 1999.

2. Clark, A. C. \& Scales, A. Y. (1999). Taking the pulse of the profession. Proceedings of the $53^{\text {rd }}$ Midyear Conference of the Engineering Design Graphics Division of the American Society for Engineering Education, Columbus, Ohio, January 15-17, 1999.

3. Branoff, T. J. \& Hartman, N. W. (2002). The 3D Model Centered Curriculum: Where Are We Now? Proceedings of the $56^{\text {th }}$ Midyear Conference of the Engineering Design Graphics Division of the American Society for Engineering Education, San Francisco, California, January 6 - 9, 2002.

4. Greco, J. (2000, September). Thinking tools. Computer Graphics World, 23 (9). pp. 49 - 52.

5. Greco, J. (2001, November). Getting smart. Computer Graphics World, 24 (11). pp. 38 - 43.

6. Dean, A. (2000, November). Intelligent data translation: How close are we? http://www.cadserver.co.uk/common/viewer/archive/2000/Nov/1/feature4.phtm

7. Barr, R. E. (1999). Planning the EDG curriculum for the $21^{\text {st }}$ century: A proposed team effort. Engineering Design Graphics Journal, 63(2), 4-12.

8. Ault, H. K. (1999). 3-D geometric modeling for the $21^{\text {st }}$ century. Engineering Design Graphics Journal, 63(2), 33-42.

9. Connolly, P. E., Ross, W. A. \& Bannatyne, M. W. (1999). Applied 3D modeling technology instruction for freshman computer graphics majors: Developing a foundational knowledge. Paper presented at the $54^{\text {th }}$ Midyear Conference of the Engineering Design Graphics Division of the American Society for Engineering Education, Biloxi, Mississippi, November 6-9, 1999.

10. Duff, J.M. (1990). Teaching engineering graphics as a body of knowledge. Proceedings of the $44^{\text {th }}$ Midyear Conference of the Engineering Design Graphics Division of the American Society for Engineering Education, Tempe, Arizona, 1990.

11. Cumberland, R. R. (2001). The foundation of a progressive engineering graphics curriculum: A directed project report. Unpublished masters thesis, Purdue University, West Lafayette.

12. Gredler, M. E. (2001). Information Processing Theories. In Learning and instruction: Theory in to practice $\left(4^{\text {th }}\right.$ ed.). Upper Saddle River, NJ: Merrill Prentice-Hall.

Proceedings of the 2004 American Society for Engineering Education Annual Conference \& Exposition Copyright C 2004, American Society for Engineering Education 
Session 2238

13. Johnson-Laird, P.N. (1983). Mental models: Towards a cognitive science of language, inference and consciousness. Cambridge, MA: Harvard University Press.

14. Keller, C.M. \& Keller, J.D. (1996). Cognition and tools use: The blacksmith at work. Cambridge, UK: Cambridge University Press.

15. Ericsson, K.A. \& Smith, J. (1991). Prospects and limits of the empirical study of expertise: An introduction. In K.A. Ericsson \& J. Smith (Ed.) Toward a general theory of expertise (p. 1-38). Cambridge: Cambridge University Press.

16. Chi, M.T.H., Glaser, R. \& Farr, M.J.. (1988). The nature of expertise. Hillsdale, NJ: Lawrence Erlbaum Associates.

17. Feltovich, P.J., Ford, K.M., \& Hoffman, R.R. (1997). Introduction. In P.J. Feltovich, K.M. Ford, \& R.R.Hoffman (Eds.) Expertise in context: Human and machine (p. xiii-xviii). Cambridge, MA: AAAI Press/The MIT Press.

18. Glaser, R. \& Chi, M.T.H. (1988). Introduction. In M.T.H. Chi, R. Glaser, \& M.J. Farr (Eds.) The Nature of Expertise. Hillsdale, NJ: Lawrence Erlbaum Associates.

19. Mieg, H.A. (2001). The social psychology of expertise: Case studies in research, professional domains, and expert roles. Mahwah, NJ: Lawrence Earlbaum and Associates.

20. Bhavnani, S.K. \& John, B.E. (1996). Exploring the unrealized potential of computer-aided drafting. Proceedings of CHI '96, 332-339.

21. Bhavnani, S.K. \& John, B.E. (1997). From sufficient to efficient usage: An analysis of strategic knowledge. Proceedings of $\mathrm{CHI}$ '97, 91-98.

22. Bhavnani, S.K. \& John, B.E. (1998). Delegation and circumvention: Two faces of efficiency. Proceedings of CHI '98, 273-280.

23. Bhavnani, S.K., John, B.E., \& Flemming, U. (1999). The strategic use of CAD: An empirically inspired, theorybased course. Proceedings of CHI '99, 183-190.

24. McGraw, K.L. \& Harbison-Briggs, K. (1989). Knowledge acquisition: Principles and guidelines. Englewood Cliffs, NJ: Prentice Hall.

25. Giesecke, F.E., Mitchell, A., Spencer, H.C., Hill, I.L., Dygdon, J.T., \& Novak, J.E. (1993). Technical Drawing ( $9^{\text {th }}$ ed.). New York, NY: Macmillan Publishing Company.

26. Olson, J. R. \& Biolsi, K.J. (1991). Techniques for representing expert knowledge. In K.A. Ericsson \& J. Smith (Ed.) Toward a general theory of expertise (p. 240-285). Cambridge: Cambridge University Press.

27. Hoffman, R.R., Shadbolt, N. R., Burton, A.M., \& Klein, G. (1995). Eliciting knowledge from experts: A methodological analysis. Organizational Behavior and Human Decision Processes, 62(2), 129-158.

28. Polkinghorne, D.E. (1989). Phenomenological research methods. In R.S. Valle \& S. Halling (Eds.), Existentialphenomenological perspectives in psychology (pp. 41-60). New York: Plenum.

29. Meyer, M.A. \& Booker, J.M. (1991). Eliciting and analyzing expert judgment: A practical guide (Volume 5). San Diego, CA: Academic Press.

30. Vincenti, W.G. (1990). What engineers know and how they know it: Analytical studies from aeronautical history. Baltimore, MD: The Johns Hopkins University Press.

\section{NATHAN W. HARTMAN}

Nate Hartman is an Assistant Professor in the Department of Computer Graphics at Purdue University. He teaches courses in introductory engineering graphics, 3D solid and surface modeling, and engineering graphics standards and documentation. While working for Rand Worldwide, Nate helped integrate CAD into the engineering design process of many companies through the development of custom training applications and materials. His academic interests include the use of constraint-based CAD tools in the design process, the development of expertise in the use of CAD tools, spatial visualization ability, and the development of visual science as a discipline.

Proceedings of the 2004 American Society for Engineering Education Annual Conference \& Exposition Copyright (C) 2004, American Society for Engineering Education 